\title{
Validation of non-invasive central blood pressure devices: Artery Society task force (abridged) consensus statement on protocol standardization
}

James E. Sharman, ${ }^{1 *}$ Alberto P. Avolio, ${ }^{2}$ Johannes Baulmann, ${ }^{3}$ Athanase Benetos, ${ }^{4}$ Jacques Blacher, ${ }^{5}$ C. Leigh Blizzard, ${ }^{1}$ Pierre Boutouyrie,${ }^{6}$ Chen-Huan Chen, ${ }^{7}$ Phil Chowienczyk, ${ }^{8}$ John R. Cockcroft, ${ }^{9}$ J. Kennedy Cruickshank, ${ }^{10}$ Isabel Ferreira, ${ }^{11}$ Lorenzo Ghiadoni, ${ }^{12}$ Alun Hughes, ${ }^{13}$ Piotr Jankowski, ${ }^{14}$ Stephane Laurent, ${ }^{6}$ Barry J. McDonnell, ${ }^{9}$ Carmel McEniery, ${ }^{15}$ Sandrine C. Millasseau, ${ }^{16}$ Theodoros G. Papaioannou, ${ }^{17}$ Gianfranco Parati, ${ }^{18}$ Jeong Bae Park, ${ }^{19}$ Athanase D. Protogerou ${ }^{20}$ Mary J. Roman, ${ }^{21}$ Giuseppe Schillaci, ${ }^{22}$ Patrick Segers,${ }^{23}$ George S. Stergiou, ${ }^{24}$ Hirofumi Tomiyama ${ }^{25}$ Raymond R. Townsend, ${ }^{26}$ Luc M. Van Bortel, ${ }^{27}$ Jiguang Wang, ${ }^{28}$ Siegfried Wassertheurer,${ }^{29}$ Thomas Weber, ${ }^{30}$ Ian B. Wilkinson, ${ }^{15}$ Charalambos Vlachopoulos. ${ }^{31}$

\footnotetext{
${ }^{1}$ Menzies Institute for Medical Research, University of Tasmania, Hobart, Australia.

${ }^{2}$ Department of Biomedical Sciences, Faculty of Medicine and Health Sciences, Macquarie University, Sydney, Australia.

${ }^{3}$ Clinic of Internal Medicine II, University Hospital Schleswig-Holstein, Luebeck, Germany. ${ }^{4}$ Département de Médecine Gériatrique, CHRU de Nancy, and INSERM U1116, Université
} de Lorraine, Vandoeuvre-les-Nancy, France.

${ }^{5}$ Hypertension and cardiovascular prevention unit; Hôtel-Dieu university Hospital; Assistance Publique-Hôpitaux de Paris; University Paris Descartes, Paris, France.

${ }^{6}$ Departments of Pharmacology, European Georges Pompidou Hospital, Assistance Publique Hôpitaux de Paris, Inserm UMR 970 and University Paris Descartes, Paris, France.

${ }^{7}$ Department of Medicine, Faculty of Medicine, National Yang-Ming University, Taipei, Taiwan, ROC.

${ }^{8}$ Department of Clinical Pharmacology, King's College London British Heart Foundation Centre, UK.

${ }^{9}$ Department of Biomedical Sciences, School of Health Sciences, Cardiff Metropolitan University, Cardiff, UK.

${ }^{10}$ Cardiovascular Medicine Group, Division of Diabetes and Nutritional Sciences, King's College, London, UK.

${ }^{11}$ The University of Queensland, School of Public Health, Herston, Brisbane, Australia.

${ }^{12}$ Department of Clinical and Experimental Medicine, University of Pisa, Pisa, Italy.

${ }^{13}$ Institute of Cardiovascular Science, University College London, UK.

${ }^{14}$ First Department of Cardiology and Hypertension, Institute of Cardiology, Jagiellonian University Medical College, Poland.

${ }^{15}$ Division of Experimental Medicine and Immunotherapeutics, Department of Medicine, University of Cambridge, Cambridge, UK.

${ }^{16}$ Pulse Wave Consulting, Saint Leu la Foret, France.

${ }^{17}$ Biomedical Engineering Unit, First Department of Cardiology, Hippokration Hospital, Medical School, National and Kapodistrian University of Athens, Greece.

${ }^{18}$ Department of Cardiology, S.Luca Hospital, Istituto Auxologico Italiano; Department of Medicine and Surgery, University of Milano-Bicocca, Milan, Italy.

${ }^{19}$ Department of Medicine/Cardiology, Cheil General Hospital, Dankook University College of Medicine, Seoul, Korea. 
${ }^{20}$ Cardiovascular Prevention and Research Unit, Department of Pathophysiology, 'Laiko' Hospital, Medical School, National and Kapodistrian University of Athens, Greece.

${ }^{21}$ Division of Cardiology, Department of Medicine, Weill Cornell Medical College, New York, NY, USA.

${ }^{22}$ Dipartimento di Medicina, Università di Perugia; Unità di Medicina Interna, Ospedale 'S. Maria', Terni, Italy.

${ }^{23}$ IBiTech-bioMMeda, Ghent University, Ghent, Belgium.

${ }^{24}$ Hypertension Center STRIDE-7, National and Kapodistrian University of Athens, Third Department of Medicine, Sotiria Hospital, Athens, Greece.

${ }^{25}$ Department of Cardiology, Tokyo Medical University, Tokyo, Japan.

${ }^{26}$ Perelman School of Medicine, University of Pennsylvania, Philadelphia, PA, USA.

${ }^{27}$ Heymans Institute of Pharmacology, Ghent University, Ghent, Belgium.

${ }^{28}$ The Shanghai Institute of Hypertension, Ruijin Hospital, Shanghai Jiaotong University School of Medicine, Shanghai, China.

${ }^{29}$ Austrian Institute of Technology, Health \& Environment Department, Vienna, Austria

${ }^{30}$ Cardiology Department, Klinikum Wels-Grieskirchen, Wels, Austria.

${ }^{31}$ First Department of Cardiology, Hippokration Hospital, Medical School, National and Kapodistrian University of Athens, Greece.

\section{*Corresponding author.}

James Sharman

Menzies Institute for Medical Research, University of Tasmania, Hobart, Australia

Phone: +61 3 62264709. Email: james.sharman@utas.edu.au

Acknowledgements: The task force is grateful for the contribution by the European Society of Hypertension (ESH) Working Group on Arterial Structure and Function, and the ESH Working Group on Blood Pressure Monitoring and Cardiovascular Variability. 


\begin{abstract}
Brachial cuff blood pressure (BP) is clinically important, but may be an inaccurate substitute for central BP. Many non-invasive devices have been developed that purport to estimate central BP from peripheral artery sites, yet with no standardized guidelines; the accuracy testing of these new devices has not been undertaken in a uniform fashion with comparable protocols. This is an abridged paper describing the recommendations reached by an international task force convened to identify issues that need to be addressed and reach consensus relating to methods for assessing and reporting the accuracy (validation) of central BP devices. The recommendations are endorsed by the Association for Research into Arterial Structure and Physiology (ARTERY) Society, as well as the European Society of Hypertension (ESH) Working Group on Arterial Structure and Function, and the ESH Working Group on Blood Pressure Monitoring and Cardiovascular Variability.
\end{abstract}

Keywords: guideline, aorta, diagnostic equipment, hypertension, central blood pressure. 


\section{Introduction}

The original Riva-Rocci method to measure blood pressure (BP) using a cuff at the upper arm assumed the pressure obtained by this technique was a good proxy for central aortic BP. ${ }^{1,2}$ The clinical (prognostic) importance of brachial cuff BP is undeniable for both the assessment of cardiovascular risk associated with elevated $\mathrm{BP}$ and the benefits of treatment-induced BP reduction. ${ }^{3}$ However, it is also generally appreciated that peripheral artery systolic BP (SBP; brachial or radial artery) may be an inaccurate substitute for central SBP. ${ }^{4}$ This has been reported in human studies using intra-arterial catheterization of peripheral and central arteries. ${ }^{5-}$

${ }^{8}$ There may also be a discrepancy between peripheral and central BP responses to vasoactive drugs. ${ }^{9}$ These findings are corroborated in larger studies using non-invasive central aortic BP methods, ${ }^{10-13}$ and, while yet to be fully adopted in clinical practice, an independent prognostic value of central BP has been demonstrated. ${ }^{14-16}$ Altogether, there is a growing interest among clinicians toward improving risk estimates by using devices that provide more accurate measures of central aortic BP than those provided by current brachial cuff BP methods.

Many non-invasive devices have been developed that purport to estimate central BP from different peripheral artery sites (e.g. radial, brachial, carotid arteries) using different principles of recording the pressure or surrogate signals (e.g. applanation tonometry, oscillometry, ultrasound or magnetic resonance imaging) and different calibration methods to derive central BP. Since upper arm cuff-based devices to estimate central BP are more clinically appealing, in recent years several companies have developed such devices using a variety of techniques (e.g. oscillometric sub-diastolic or supra-systolic waveform analysis with generalized transfer functions), which employ a variety of signal processing steps to estimate central BP from peripheral signals. ${ }^{17,} 18$ Yet, with no standardized guidelines, ${ }^{17}$ the accuracy testing of these new devices (as well as the preceding devices) has not been undertaken in a 
uniform fashion with comparable protocols, emphasizing the need for guidance in this field. ${ }^{19-}$

${ }^{22}$ An international task force was convened to address this situation.

\section{Task force aims}

1. To identify issues that need to be addressed and reach consensus relating to methods for assessing and reporting the accuracy of central BP devices.

2. To provide recommendations regarding appropriate protocols to assess and report the evaluation of accuracy (validation) of central BP devices.

The full report of the task force was recently published ${ }^{23}$ and in this abridged version, the majority of information is presented in summary format within Tables. Table 1 gives a glossary of terms and a summary of issues and recommendations is provided in Table 2. A summary of differences between device types in comparison to intra-arterial brachial and central aortic BP are presented in Figure 1.

\section{Validation protocol requirements}

Several scientific bodies have developed validation protocols for non-invasive peripheral BP monitors, ${ }^{24-29}$ yet they differ on procedural features such as sample size and selection criteria, number of assessment phases, acceptable margin of error, BP range and pass/fail criteria. ${ }^{30} \mathrm{~A}$ 'universal' brachial BP validation protocol is under development through collaboration of the American Association for the Advancement of Medical Instrumentation (AAMI), the International Organization for Standardisation (ISO) and the ESH Working Group on Blood Pressure Monitoring and Cardiovascular Variability, and projected to be in effect in 2018. This harmonised protocol is expected to inform many aspects of central BP validation protocols that equally apply to brachial BP (e.g. age, gender, BP range), but an internationally accepted central BP protocol directed by regulatory authorities is still required, as distinct from the forthcoming brachial BP protocol. 
Recommendations focus on central BP specific protocol requirements, with some relevant features drawn from existing validation guidelines. ${ }^{24-26}$ For unambiguous interpretation of requirements, facets of the protocol have been listed in terms of "must," "should" and "may." "Must" indicates a necessary component for highest quality, "should" indicates a strong recommendation, but may not be the only way that the component can be achieved, and "may" is used to provide further guidance. Protocol requirements are summarised in Table 3 as a pro-forma guide for investigators. Less attention is given to protocol features equally relevant to brachial BP (i.e. sample characteristics, results reporting and pass criteria) but some proposed direction is also provided based on existing guidelines ${ }^{24-}$ 26 for interim guidance (and to highlight outstanding issues) prior to development of an accepted international central BP validation protocol. A list of issues in need of resolution in the future development of such a protocol is provided in Table 4.

Sample characteristics. A sample size of at least $n=85$ adults is proposed based on brachial BP validation protocols and the requirement to detect a mean difference of $5 \mathrm{mmHg}$ (standard deviation $\left(\mathrm{S}_{\mathrm{d}}\right)$ of the difference $8 \mathrm{mmHg}$ ) with an estimated power of $>99 \%$ (two-sided alpha of 5\%), as currently proposed by the AAMI standard. Nevertheless, invasive BP measures during clinical procedures face additional constraints that can increase BP variability, such as selective patient characteristics and limited time for repeat measurements. Thus, a definitive sample size based on robust statistical methods is still needed. If devices are to be used in paediatric age groups, then wherever possible, accuracy should be tested separately in those groups and not extrapolated from adults. Participants should have a sex distribution of at least $30 \%$ male and female and in sinus rhythm unless the device is being tested for accuracy during arrhythmias. ${ }^{25}$ In keeping with all other brachial cuff BP validation guidelines, devices should be tested over a range of BP. An indicative range for invasive central SBP may be $\leq 100 \mathrm{mmHg}$ ( $\geq 5 \%$ of readings), $\geq 140 \mathrm{mmHg}(\geq 20 \%$ of readings) and $\geq 160 \mathrm{mmHg}(\geq 5 \%$ of readings $)$, and 
the indicative range for invasive central DBP may be $\leq 60 \mathrm{mmHg}$ ( $\geq 5 \%$ of readings), $\geq 85$ $\mathrm{mmHg}(\geq 20 \%$ of readings $)$ and $\geq 100 \mathrm{mmHg}(\geq 5 \%$ of readings $) .{ }^{24}$ Device accuracy should also be tested across a range of heart rates (i.e. 60 to $100 \mathrm{bpm}$ ), because heart rate influences aortic stiffness and SBP amplification. ${ }^{31,32}$ Exact criteria for BP and heart rate ranges needs to be resolved. Unless testing device performance in specific cardiac or respiratory diseases, it should be noted that subjects with the following conditions have a higher likelihood of measurement error due to abnormal haemodynamics: severe valvular stenosis or regurgitation, severely impaired left ventricular systolic function, atrial fibrillation, constrictive pericarditis, pericardial tamponade, restrictive cardiomyopathy or severe pulmonary disease.

Statistical requirements. Beyond the reporting of details already mentioned, description of subjects must be presented and should include basic demographics (age, sex, ethnicity, body mass index), medications and clinical conditions including outcome of coronary catheterization procedure. Comparison between non-invasive and reference BP's must report mean difference, $\mathrm{S}_{\mathrm{d}}$ of the mean difference, and limits of agreement (LOA), illustrated by modified BlandAltman plots $^{33}$ in which the mean of measurements is replaced by the reference catheter measurement. Scatter plots of the measures obtained with the non-invasive device (on Y axis) versus the reference method (on $\mathrm{X}$ axis), with the line of equality, may also be provided for descriptive purposes. Non-uniformity of $S_{d}$ across the range of measurement or evidence of non-constant bias (e.g. increasing difference between measures with increasing values) must be visually checked on the Bland-Altman plots. An increase in variability of the differences as the magnitude of the measurement increases can be dealt with by log transformation of both measurements before analysis and the LOA derived from log transformed data should be reported after back-transformation (and thus expressed as ratios of the actual measurements). When log transformations do not solve the problem of a relationship between the difference and the mean, regression approaches or non-parametric approaches can be used instead, but 
with preference for the latter (for details see ${ }^{33}$ ). Absolute BP differences from the reference should be presented as a clinically meaningful illustration of the results but without a pass/fail criteria. ${ }^{24}$ The proposed pass criteria is if the device has a mean difference of $\leq 5 \mathrm{mmHg}$ with $\mathrm{S}_{\mathrm{d}} \leq 8 \mathrm{mmHg}$ compared with the reference, based on the magnitude of minimum tolerable error and frequency, ${ }^{24}$ but also recognizing this is a feature requiring resolution in future guidelines.

\section{Conclusions and future directions}

A major reason for producing this document to improve device validity has been the ongoing controversy over whether central BP adds prognostic value to that from routine brachial cuff BP. A recent Framingham paper found no additional value,${ }^{34}$ while two systematic reviews not including those data came to opposite conclusions. ${ }^{14,} 35$ For unfamiliar readers, an accompanying editorial addresses the issues. ${ }^{36}$ A number of perceived deficits relating to both brachial and central BP measurement have been brought to attention in this current paper, and accordingly some points of intent require additional explanation. Firstly, despite the premise of clinical brachial BP measurement being based on essentially inaccurate cuff measures, brachial BP is still important and regarded as the clinical standard. This document should not be interpreted as challenging the clinical utility of brachial BP measurement, nor its value in hypertension management. Similarly, this document does not seek to undermine the potential clinical use of currently available non-invasive central BP devices that have not undergone the validation procedures recommended in this document, but have already proven to provide measurement of physiological (e.g. vascular ageing) ${ }^{37}$ or prognostic significance. Nevertheless, with the advent of "precision medicine," clinical decisions are expected to be refined and improved by using more accurate BP monitors into the future, whether brachial or central BP, and this is a key research need. Additional guidance on central BP validation protocols is keenly awaited from regulatory authorities. 


\section{Conflict of interest:}

A.Avolio has received equipment for research from BPLab and AtCor Medical

J.Blacher has received equipment for research projects from AtCor Medical.

C.Chen has received funding and equipment for research projects from Omron Corporation and Microlife Corporation.

P.Chowienczyk and King's College London have an interest in Centron Diagnostics.

J.Cockcroft has received equipment and travel grants from I.E.M. GmbH, Philips Healthcare. I.Ferreira none.

A.Hughes has received loans of equipment from ALOKA/Hitachi Medical Systems, AtCor Medical, Finapres Medical Systems, I.E.M. GmbH, Philips Healthcare, Pulsecor Ltd, SpaceLabs/Dolby and USCOM.

B.McDonnell has received equipment from AtCor Medical and I.E.M. GmbH, Philips Healthcare.

S.Millasseau has received revenue from ALAM Medical, AtCor Medical, Omron and Esaote. T.G.Papaioannou has received equipment from I.E.M. GmbH.

G.Parati has conducted validation studies for various manufacturers and is a member of the advisory board of Medaval.

J.Park has received equipment for research projects from Fukuda Denshi.

A.Protogerou has received funding and equipment for research projects from AtCor Medical and I.E.M. GmbH.

M.Roman none.

P.Segers has received equipment for research projects from Fukuda Denshi.

G.Stergiou has conducted validation studies for various manufacturers; advised manufacturers on device development, and is deputy chairman of the advisory board of Medaval. 
G.Schillaci has received funding and equipment for research projects from AtCor Medical and I.E.M. GmbH, Philips Healthcare.

J.Sharman has received funding and equipment for research projects from AtCor Medical, I.E.M. GmbH, Philips Healthcare and Pulsecor. Completion of this work was made possible through funding from the High Blood Pressure Research Council of Australia FrancoAustralian Exchange Program, the Menzies Institute for Medical Research and a Mobility Scholarship from L'Institut Servier.

R.R. Townsend none.

L.Van Bortel none.

C.Vlachopoulos has received equipment and honoraria from AtCor Medical and Omron. J.Wang has received funding and equipment for research projects from Omron.

T.Weber has received an unrestricted grant for a multicentre study as well as lecture fees from I.E.M. GmbH, Germany.

I.Wilkinson none. 


\section{References}

[1] Booth J. A short history of blood pressure measurement. Proc R Soc Med. 1977;70:793799.

[2] Karamanou M, Papaioannou TG, Tsoucalas G, Tousoulis D, Stefanadis C, Androutsos G. Blood pressure measurement: lessons learned from our ancestors. Curr Pharm Des. 2015;21:700-704.

[3] Mancia G, Fagard R, Narkiewicz K, Redón J, Zanchetti A, Böhm M, Christiaens T, Cifkova R, De Backer G, Dominiczak A, Galderisi M, Grobbee DE, Jaarsma T, Kirchhof P, Kjeldsen SE, Laurent S, Manolis AJ, Nilsson PM, Ruilope LM, Schmieder RE, Sirnes PA, Sleight P, Viigimaa M, Waeber B, Zannad F. 2013 ESH/ESC Guidelines for the management of arterial hypertension: The Task Force for the management of arterial hypertension of the European Society of Hypertension (ESH) and of the European Society of Cardiology (ESC). J Hypertens. 2013;31:1281-1357.

[4] Avolio AP, Van Bortel LM, Boutouyrie P, Cockcroft JR, McEniery CM, Protogerou AD, Roman MJ, Safar ME, Segers P, Smulyan H. Role of pulse pressure amplification in arterial hypertension: experts' opinion and review of the data. Hypertension. 2009;54:375-383.

[5] Kroeker EJ, Wood EH. Comparison of simultaneously recorded central and peripheral arterial pressure pulses during rest, exercise and tilted position in man. Circ Res. 1955;3:623632.

[6] Kroeker EJ, Wood EH. Beat-to-beat alterations in relationship of simultaneously recorded central and peripheral arterial pressure pulses during Valsalva maneuver and prolonged expiration in man. J Appl Physiol. 1956;8:483-494. 
[7] Rowell LB, Brengelmann GL, Blackmon JR, Bruce RA, Murray JA. Disparities between aortic and peripheral pulse pressures induced by upright exercise and vasomotor changes in man. Circulation. 1968;37:954-964.

[8] Cheng HM, Sung SH, Shih YT, Chuang SY, Yu WC, Chen CH. Measurement of central aortic pulse pressure: noninvasive brachial cuff-based estimation by a transfer function vs. a novel pulse wave analysis method. Am J Hypertens. 2012;25:1162-1169.

[9] Kelly RP, Gibbs HH, O'Rourke MF, Daley JE, Mang K, Morgan JJ, Avolio AP. Nitroglycerin has more favourable effects on left ventricular afterload than apparent from measurement of pressure in a peripheral artery. Eur Heart J. 1990;11:138-144.

[10] McEniery CM, Yasmin, McDonnell B, Munnery M, Wallace SM, Rowe CV, Cockcroft JR, Wilkinson IB. Central Pressure: Variability and Impact of Cardiovascular Risk Factors. The Anglo-Cardiff Collaborative Trial II. Hypertension. 2008;6:1476-1482.

[11] Sharman JE, Stowasser M, Fassett RG, Marwick TH, Franklin SS. Central blood pressure measurement may improve risk stratification. J Hum Hypertens. 2008;Dec 22:838844.

[12] Protogerou AD, Papaioannou TG, Lekakis JP, Blacher J, Safar ME. The effect of antihypertensive drugs on central blood pressure beyond peripheral blood pressure. Part I: (Patho)-physiology, rationale and perspective on pulse pressure amplification. Curr Pharm Des. 2009; 15:267-271.

[13] Herbert A, Cruickshank JK, Laurent S, Boutouyrie P. Establishing reference values for central blood pressure and its amplification in a general healthy population and according to cardiovascular risk factors. Eur Heart J. 2014;35:3122-3133.

[14] Vlachopoulos C, Aznaouridis K, O'Rourke MF, Safar ME, Baou K, Stefanadis C.

Prediction of cardiovascular events and all-cause mortality with central haemodynamics: a systematic review and meta-analysis. Eur Heart J. 2010;15:1865-1871. 
[15] Cheng H-M, Chuang S-Y, Sung S-H, Yu W-C, Pearson A, Lakatta EG, Pan W-H, Chen

C-H. Derivation and validation of diagnostic thresholds for central blood bressure measurements based on long-term cardiovascular risks. J Am Coll Cardiol. 2013;62:17801787.

[16] Huang CM, Wang KL, Cheng HM, Chuang SY, Sung SH, Yu WC, Ting CT, Lakatta EG, Yin FC, Chou P, Chen CH. Central versus ambulatory blood pressure in the prediction of all-cause and cardiovascular mortalities. J Hypertens. 2011;29:454-459.

[17] Millasseau S, Agnoletti D. Non-invasive estimation of aortic blood pressures: a close look at current devices and methods. Curr Pharm Des. 2015;21:709-718.

[18] McEniery CM, Cockcroft JR, Roman MJ, Franklin SS, Wilkinson IB. Central blood pressure: current evidence and clinical importance. European Heart Journal. 2014;35:17191725.

[19] Papaioannou TG, Protogerou A, Stefanadis C. Comparison between Mobil-O-Graph and the SphygmoCor device for central systolic blood pressure estimation: consensus is required for 'validation protocols'. Blood Press Monit. 2012;17:259-260; author reply 260-251.

[20] Sharman JE. Central pressure should be used in clinical practice. Artery Research. 2015;9:1-7.

[21] Mitchell GF. Central pressure should not be used in clinical practice. Artery Research. 2015;9:8-13.

[22] Agnoletti D, Millasseau S, Topouchian J, Safar ME, Blacher J. Comparison of central blood pressure devices on the basis of a modified protocol of the European Society of Hypertension: application to the Centron cBP301. Blood Press Monit. 2014;19:103-108.

[23] Sharman JE, Avolio AP, Baulmann J, Benetos A, Blacher J, Blizzard CL, Boutouyrie P, Chen CH, Chowienczyk P, Cockcroft JR, Cruickshank JK, Ferreira I, Ghiadoni L, Hughes A, Jankowski P, Laurent S, McDonnell BJ, McEniery C, Millasseau SC, Papaioannou TG, Parati 
G, Park JB, Protogerou AD, Roman MJ, Schillaci G, Segers P, Stergiou GS, Tomiyama H, Townsend RR, Van Bortel LM, Wang J, Wassertheurer S, Weber T, Wilkinson IB, Vlachopoulos C. Validation of non-invasive central blood pressure devices: ARTERY Society task force consensus statement on protocol standardization. Eur Heart J. $2017 ; 38: 2805-2812$.

[24] American National Standard. Non-invasive sphygmomanometers - Part 2: Clinical validation of automated measurement type. ANSI/AAMI/ISO 81060-2:2009. Association for the Advancement of Medical Instrumentation, Arlington, Virginia: AAMI; 2009.

[25] O'Brien E, Atkins N, Stergiou G, Karpettas N, Parati G, Asmar R, Imai Y, Wang J, Mengden T, Shennan A. European Society of Hypertension International Protocol revision 2010 for the validation of blood pressure measuring devices in adults. Blood Press Monit. 2010;15:23-38.

[26] O'Brien E, Petrie J, Littler W, de Swiet M, Padfield P, Altman DG, Bland M, Coates A, Atkins N. The British Hypertension Society protocol for the evaluation of blood pressure measuring devices. J Hypertens. 1993;11 (supp 2):S43 - S62.

[27] O'Brien E, Pickering T, Asmar R, Myers M, Parati G, Staessen J, Mengden T, Imai Y, Waeber B, Palatini P, Gerin W. Working Group on Blood Pressure Monitoring of the European Society of Hypertension International Protocol for validation of blood pressure measuring devices in adults. Blood Press Monit. 2002;7:3-17.

[28] Tholl U, Anlauf M. Conscientious evaluation of measuring accuracy. Hypertension League provides approval seals for automatic blood pressure units. MMW Fortschritte der Medizin. 1999;141:45.

[29] White WB, Berson AS, Robbins C, Jamieson MJ, Prisant LM, Roccella E, Sheps SG. National standard for measurement of resting and ambulatory blood pressures with automated sphygmomanometers. Hypertension. 1993;21:504-509. 
[30] Beime B, Deutsch C, Gomez T, Zwingers T, Mengden T, Bramlage P. Validation protocols for blood pressure-measuring devices: status quo and development needs. Blood Press Monit. 2015;21:1-8.

[31] Wilkinson IB, MacCallum H, Flint L, Cockcroft JR, Newby DE, Webb DJ. The influence of heart rate on augmentation index and central arterial pressure in humans. J Physiol. 2000;525:263-270.

[32] Tan I, Spronck B, Delhaas T, Reesink K, Kiat H, Barin E, Butlin M, Avolio A. Quantification of heart rate dependency of aortic pulse wave velocity. J Hypertens. 2016;34 Suppl 2:e57.

[33] Bland JM, Altman DG. Measuring agreement in method comparison studies. Statistical methods in medical research. 1999;8:135-160.

[34] Mitchell GF, Hwang SJ, Larson MG, Hamburg NM, Benjamin EJ, Vasan RS, Levy D, Vita JA. Transfer function-derived central pressure and cardiovascular disease events: The Framingham Heart Study. . Journal of Hypertension. 2016;34:1528-1534.

[35] Kollias A, Lagou S, Zeniodi ME, Boubouchairopoulou N, Stergiou GS. Association of Central Versus Brachial Blood Pressure With Target-Organ Damage: Systematic Review and Meta-Analysis. Hypertension. 2015;67:183-190.

[36] Laurent S, Sharman JE, Boutouyrie P. Central versus peripheral blood pressure: Finding a solution. Journal of Hypertension. 2016;34:1497-1499.

[37] McEniery CM, Yasmin, Hall IR, Qasem A, Wilkinson IB, Cockcroft JR. Normal Vascular Aging: Differential Effects on Wave Reflection and Aortic Pulse Wave Velocity: The Anglo-Cardiff Collaborative Trial (ACCT). J Am Coll Cardiol. 2005;46:1753-1760. 
Figure 1. Illustration of the differences in systolic (SBP) and diastolic (DBP) blood pressure (BP) between intra-arterial brachial and central BP, brachial cuff BP and non-invasive central BP devices Types I and II (BP ranges of different methods represented by the double arrows). Red shaded area A, represents the true (intra-arterial) level of central-to-brachial SBP amplification, and red shaded area B represents the non-invasive estimated central-to-brachial SBP amplification (A and B may be similar in magnitude). The non-invasive central SBP estimated using central BP device Type II may be higher than non-invasive brachial cuff SBP, but this is due to underestimation of true (intra-arterial) brachial SBP with the cuff device and, therefore, does not reflect physiological amplification. The hatched areas denote that there will be a degree of variability in estimated BP between devices. 
Table 1. Glossary of terms.

\begin{tabular}{|c|c|}
\hline $\begin{array}{l}\text { Intra-arterial (invasive) } \\
\text { blood pressure }\end{array}$ & $\begin{array}{l}\text { Direct measurement of blood pressure within the artery } \\
\text { using an in-dwelling catheter-based pressure transducer. }\end{array}$ \\
\hline $\begin{array}{l}\text { Peripheral (non-invasive) } \\
\text { blood pressure }\end{array}$ & $\begin{array}{l}\text { Blood pressure at a site distal from the aorta. This most } \\
\text { often refers to brachial or radial artery blood pressure, } \\
\text { but for the purpose of this paper also includes carotid } \\
\text { blood pressure even though local derivation is regarded } \\
\text { as a surrogate of central blood pressure. }\end{array}$ \\
\hline $\begin{array}{l}\text { Central (aortic) blood } \\
\text { pressure }\end{array}$ & Blood pressure in the proximal ascending aorta. \\
\hline $\begin{array}{l}\text { Systolic blood pressure } \\
\text { amplification }\end{array}$ & $\begin{array}{l}\text { The increase in systolic blood pressure from proximal to } \\
\text { peripheral arterial vessels (e.g. aorta-to-brachial, or } \\
\text { brachial-to-radial arteries). }\end{array}$ \\
\hline Transfer function & $\begin{array}{l}\text { Signal processing step to estimate central blood pressure } \\
\text { waveforms from peripherally recorded waveforms. }\end{array}$ \\
\hline Calibration & Process of scaling a waveform using units of pressure. \\
\hline
\end{tabular}


Table 2. Summary of issues in the assessment and reporting of central blood pressure (BP) monitors and recommendations.

\begin{tabular}{|c|c|}
\hline Issue & Recommendation \\
\hline $\begin{array}{l}\text { 1. Disparity of non-invasive central BP devices } \\
\text { as to what is being measured }\end{array}$ & $\begin{array}{l}\text { Device manufacturers should clearly state the purported measurement } \\
\text { function of their device. These can be broadly categorized into two types } \\
\text { based on function: Type I - estimates central BP relative to measured } \\
\text { brachial BP; Type II - estimates intra-arterial central BP. } \\
\text { Both function types may be available within a single device. }\end{array}$ \\
\hline $\begin{array}{l}\text { 2. Calibration of peripheral artery signals } \\
\text { using brachial cuff BP }\end{array}$ & $\begin{array}{l}\text { To achieve accurate non-invasive assessment of true central BP, more } \\
\text { accurate non-invasive estimates of intra-arterial brachial BP are needed. } \\
\text { Establishing more rigorous accuracy criteria for brachial BP is desirable. } \\
\text { Current evidence suggests that calibration with MAP and DBP may provide } \\
\text { a more accurate assessment of central BP than calibration with SBP and } \\
\text { DBP. }\end{array}$ \\
\hline 3. Disparity in validation standards & $\begin{array}{l}\text { The reference standard against which device accuracy of central BP estimation } \\
\text { is gauged should be intra-arterial catheter in the ascending aorta. Details of the } \\
\text { calibration method should be provided. If the brachial BP waveform } \\
\text { undergoes recalibration to produce a 'new' brachial BP, then the recalibrated } \\
\text { brachial BP values (and the method to derive them) should also be provided } \\
\text { so that the level of estimated aorta-to-brachial systolic BP amplification can } \\
\text { be gauged. }\end{array}$ \\
\hline $\begin{array}{l}\text { 4. Limitations in performing invasive } \\
\text { validation studies }\end{array}$ & $\begin{array}{l}\text { In future, it may be reasonable to use non-invasive central BP devices as } \\
\text { reference standards, but the acceptance criteria for this are yet to be } \\
\text { determined. }\end{array}$ \\
\hline
\end{tabular}


Table 3. Summary of central blood pressure (BP) device validation protocol components and requirements.

\begin{tabular}{|c|c|c|c|}
\hline Protocol Section & Protocol Item & Protocol Requirement & $\begin{array}{c}\text { Protocol Undertaken } \\
\text { (circle yes/no .....comment) }\end{array}$ \\
\hline Study setting & $\begin{array}{l}\text { Isolated room without } \\
\text { disturbing influences. }\end{array}$ & Should & $\begin{array}{l}\text { YES } \\
\text { NO } \ldots \ldots \ldots \ldots \ldots \ldots \ldots \ldots \ldots \ldots \ldots \ldots \ldots \ldots \ldots\end{array}$ \\
\hline \multirow[t]{6}{*}{$\begin{array}{l}\text { Non-invasive central BP } \\
\text { device measurement } \\
\text { standards }\end{array}$} & $\begin{array}{l}\text { List manufacturer, model, } \\
\text { software version, operating } \\
\text { principles, signal processing } \\
\text { step/s, calibration processes. }\end{array}$ & Must & $\begin{array}{l}\text { YES } \\
\text { NO } \ldots \ldots \ldots \ldots \ldots \ldots \ldots \ldots \ldots \ldots \ldots \ldots \ldots \ldots \ldots\end{array}$ \\
\hline & $\begin{array}{l}\text { Time for BP measures; time } \\
\text { points of brachial BP and } \\
\text { central BP; cuff deflation } \\
\text { speed. }\end{array}$ & Should & $\begin{array}{l}\text { YES } \\
\text { NO... }\end{array}$ \\
\hline & $\begin{array}{l}\text { Define and use appropriate } \\
\text { cuff size. }\end{array}$ & Must & $\begin{array}{l}\text { YES } \\
\text { NO... }\end{array}$ \\
\hline & $\begin{array}{l}\text { Dimensions of inflatable } \\
\text { bladder for all cuff sizes } \\
\text { available; process to } \\
\text { determine cuff size. }\end{array}$ & Should & $\begin{array}{l}\text { YES } \\
\text { NO... }\end{array}$ \\
\hline & $\begin{array}{l}\text { Process of familiarisation with } \\
\text { equipment. }\end{array}$ & Should & $\begin{array}{l}\text { YES } \\
\text { NO } \ldots \ldots \ldots \ldots \ldots \ldots \ldots \ldots \ldots \ldots \ldots \ldots \ldots \ldots \ldots\end{array}$ \\
\hline & $\begin{array}{l}\text { Separate validation studies for } \\
\text { additional or optional features } \\
\text { or functions. }\end{array}$ & Must & $\begin{array}{l}\text { YES } \\
\text { NO..... }\end{array}$ \\
\hline
\end{tabular}




\begin{tabular}{|c|c|c|c|}
\hline & $\begin{array}{l}\text { Process/s of quality control; } \\
\text { process used to delineate } \\
\text { acceptable quality; number of } \\
\text { unacceptable readings; } \\
\text { reason/s for exclusion. }\end{array}$ & Must & $\begin{array}{l}\text { YES } \\
\text { NO } \ldots \ldots \ldots \ldots \ldots \ldots \ldots \ldots \ldots \ldots \ldots \ldots \ldots \ldots \ldots \ldots \ldots\end{array}$ \\
\hline \multirow[t]{3}{*}{$\begin{array}{l}\text { Invasive (intra-arterial) } \\
\text { central BP reference standard }\end{array}$} & $\begin{array}{l}\text { Micromanometer-tipped } \\
\text { catheter used if minor } \\
\text { inflection points to be } \\
\text { identified. }\end{array}$ & Should & $\begin{array}{l}\text { YES } \\
\text { NO... }\end{array}$ \\
\hline & $\begin{array}{l}\text { Full description of catheter; } \\
\text { frequency response and } \\
\text { handling procedures. }\end{array}$ & Must & $\begin{array}{l}\text { YES } \\
\text { NO... }\end{array}$ \\
\hline & $\begin{array}{l}\text { Performance comparison of } \\
\text { fluid filled catheter with } \\
\text { micromanometer-tipped } \\
\text { catheter. }\end{array}$ & May & $\begin{array}{l}\text { YES } \\
\text { NO.. }\end{array}$ \\
\hline \multirow[t]{3}{*}{ Data acquisition at rest } & $\begin{array}{l}\text { Period of undisturbed rest; } \\
\text { medications used. }\end{array}$ & Should & $\begin{array}{l}\text { YES } \\
\text { NO... }\end{array}$ \\
\hline & $\begin{array}{l}\text { No talking. Free from acute } \\
\text { hemodynamic interventions }\end{array}$ & Must & $\begin{array}{l}\text { YES } \\
\text { NO... }\end{array}$ \\
\hline & $\begin{array}{l}\text { Test device compared with } \\
\text { reference over time-period } \\
\text { matching the test device } \\
\text { deflation cycle; recorded } \\
\text { under stable conditions. }\end{array}$ & Must & 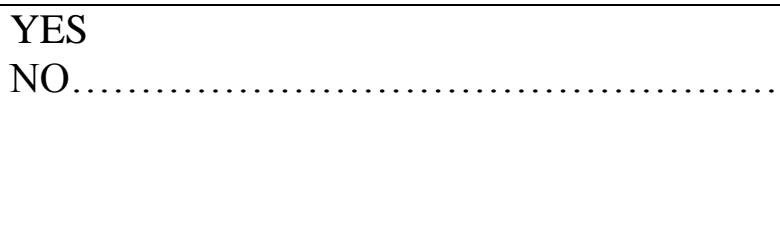 \\
\hline
\end{tabular}




\begin{tabular}{|c|c|c|c|}
\hline & $\begin{array}{l}\text { Complete description of } \\
\text { protocol; time interval } \\
\text { between test device and } \\
\text { reference measures. }\end{array}$ & Must & $\begin{array}{l}\text { YES } \\
\text { NO..................... }\end{array}$ \\
\hline \multirow[t]{2}{*}{$\begin{array}{l}\text { Data acquisition at } \mathrm{BP} \\
\text { intervention }\end{array}$} & $\begin{array}{l}\text { Hemodynamic change from } \\
\text { resting state. }\end{array}$ & May & $\begin{array}{l}\text { YES } \\
\text { NO.... }\end{array}$ \\
\hline & $\begin{array}{l}\text { Description of the } \\
\text { intervention procedure. }\end{array}$ & Must & $\begin{array}{l}\text { YES } \\
\text { NO... }\end{array}$ \\
\hline
\end{tabular}

SBP, systolic BP; DBP, diastolic BP. Complete details of protocol components and requirements are contained within the body text. Must, necessary component for highest quality; Should, strong recommendation, but probably not the only way that the component can be achieved; May, further guidance required. 
Table 4. Summary list of issues for consideration in development of an internationally accepted central blood pressure (BP) validation protocol.

\begin{tabular}{|c|c|}
\hline Validation protocol features & Comments \\
\hline $\begin{array}{l}\text { Reference method } \\
\text { Non-invasive reference standard. }\end{array}$ & $\begin{array}{l}\text { What criteria needed to satisfy for an acceptable non-invasive alternative to the invasive } \\
\text { method which restricts study sample characteristics? }\end{array}$ \\
\hline $\begin{array}{l}\text { Error } \\
\text { Minimum standard. }\end{array}$ & $\begin{array}{l}\text { What is the magnitude of the minimum acceptable error and its frequency based on the } \\
\text { invasive reference standard? }\end{array}$ \\
\hline $\begin{array}{l}\text { Study sample } \\
\text { Definition of general population sample. }\end{array}$ & $\begin{array}{l}\text { Which populations should be considered as special as there may be different device } \\
\text { measurement accuracy from the general population, and therefore require separate validation? }\end{array}$ \\
\hline $\begin{array}{l}\text { Minimum sample size for a general } \\
\text { population study. }\end{array}$ & $\begin{array}{l}\text { Based on the reference method for an acceptable statistical risk of false positive and negative } \\
\text { results. }\end{array}$ \\
\hline $\begin{array}{l}\text { Sample size for validations in special } \\
\text { groups. }\end{array}$ & To be defined after a successful study in the general population has been completed. \\
\hline Sex and age distribution. & Representation of males and females, adolescents, young and middle aged adults and elderly. \\
\hline $\mathrm{BP}$ and heart rate range criteria. & Based on reference central BP measurements and heart rate during the procedure? \\
\hline Cuff size. & $\begin{array}{l}\text { Minimum number of subjects investigated per different cuff size, or number of different cuffs } \\
\text { to be studied in a single study? }\end{array}$ \\
\hline Exclusion criteria. & $\begin{array}{l}\text { On the basis of increased reference BP variation within individual validation procedures or } \\
\text { clinical conditions. }\end{array}$ \\
\hline $\begin{array}{l}\text { Procedural } \\
\text { Number of measurements. }\end{array}$ & Procedure for the number of reference and test BP measurements in a validation session. \\
\hline Comparison with reference. & $\begin{array}{l}\text { How to compare when operating characteristics differ between reference (i.e. beat-to-beat) and } \\
\text { non-invasive test devices (i.e. averaging over seconds to minutes) and influence of respiratory } \\
\text { variation and arrhythmias? }\end{array}$ \\
\hline $\begin{array}{l}\text { Reporting } \\
\text { Data and pass criteria. }\end{array}$ & What data, statistics and study features to be reported? What pass/fail criteria? \\
\hline
\end{tabular}




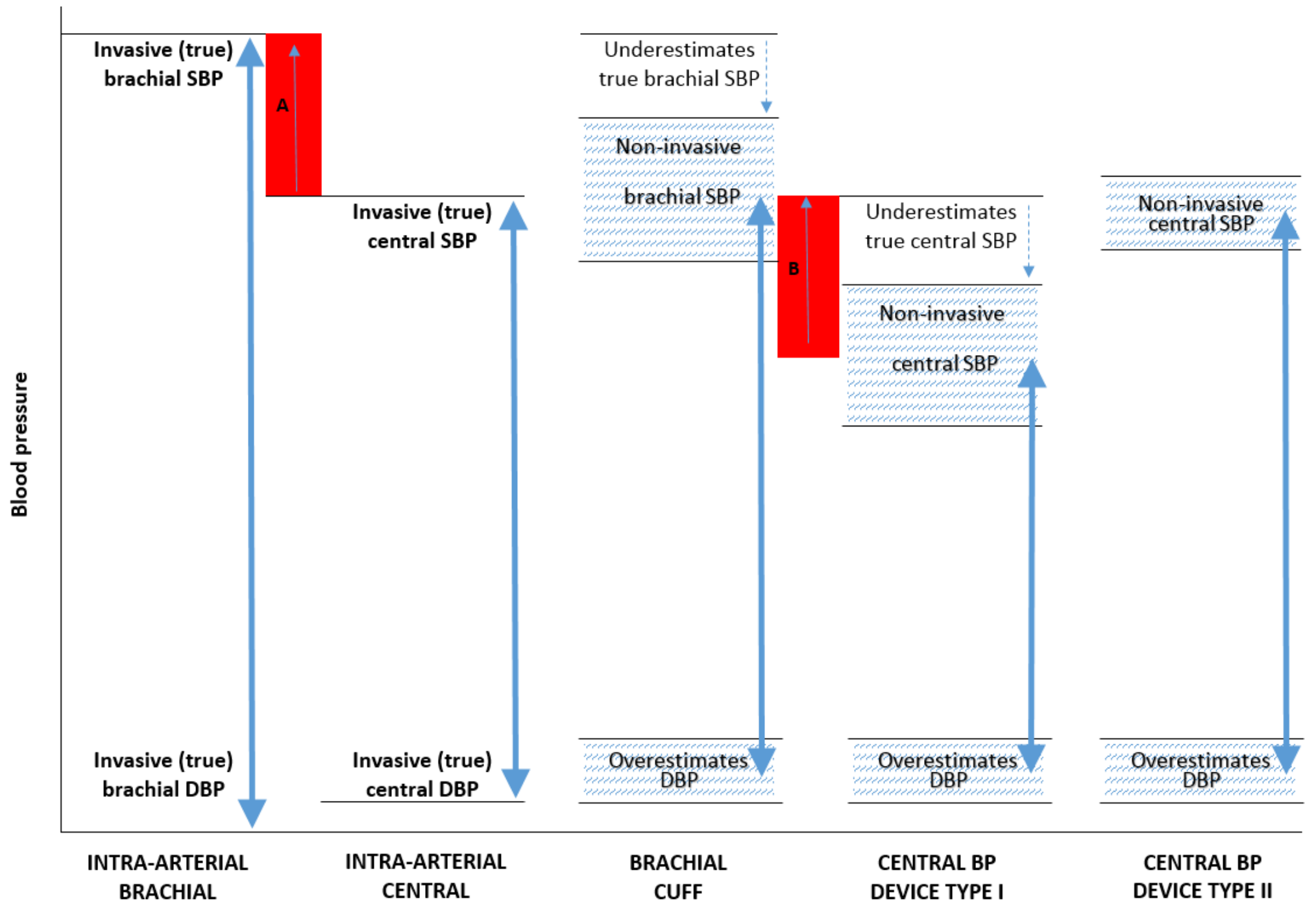

Figure 1 